\title{
Digital Imaging in Pediatric Hospitals
}

\author{
Mervyn D. Cohen
}

\begin{abstract}
Thirty-nine of 65 children's hospitals in North America responded to a questionnaire regarding their use of digital fluoroscopy and computed radiography (CR) systems. Both digital modalities are very favorably rated by institutions that have them. Budget constraints limit purchases in the other institutions. Picture archiving and communication systems (PACS) networking is not the primary reason for installation of digital systems. Fourteen of $\mathbf{3 9}$ hospitals have digital fluoroscopy and another 9 plan installation within 12 months. The three most highly rated benefits of digital fluoroscopy were decreased radiation dose, immediate visualization of the acquired image on the monitor, and the ability to alter image contrast and density. Four of $\mathbf{3 9}$ hospitals have computed radiography. The three most highly rated benefits of computed radiography were more stable image quality, ability to alter contrast and density, and PACS networking. Copyright 1992 by W.B. Saunders Company
\end{abstract}

KEY WORDS: digital imaging, pediatric radiology, digital fluoroscopy, computed tomography.

D IGITAL IMAGING TECHNIQUES offer the potential advantages of image manipulation, image transfer, and radiation dose reduction. $^{1-3}$ This potential for radiation dose reduction makes them particularly attractive for pediatric radiology.

Digital fluoroscopy uses a conventional fluoroscopic room with a digitizer attached to the television camera. This permits the direct acquisition of a digitized fluoroscopic image in place of the more conventional $100 \mathrm{~mm}$ or spot film.

Computed radiography refers to the digital acquisition of plain film radiographs. For purposes of this study computed radiography did not include the digitization of previously acquired conventional film screen radiographs. It did include the direct acquisition of digital radiographs using either a phosphor plate acquisition technology or a scanning fan beam.

This study was undertaken to evaluate how the two digital techniques of digital fluoroscopy and computed radiography are being used in free standing children's hospitals in North America.

\section{METHODS}

Sixty-five questionnaires were sent to all members of the Society of Chairmen of Radiology in Children's Hospitals. Thirty-nine replies were received.

\author{
RESULTS
}

\section{Digital Fluoroscopy}

Fourteen of the 39 hospitals had digital fluoroscopy (Table 1). These hospitals were larger (mean, 248 beds) than those hospitals without digital fluoroscopy (mean, 183 beds). This difference is not significant. Hospitals without digital fluoroscopy believed strongly that it is worthwhile but budget constraints were preventing installation (Table 2). Of the 25 hospitals without digital fluoroscopy, only nine had definite plans to install such systems within the next 12 months.

The 14 hospitals with digital fluoroscopy have a total of 34 fluoroscopic rooms. Of these, 25 are digital and nine are not. Eight of the 14 hospitals have digital capability in $100 \%$ of their fluoroscopic rooms. In the digital fluoroscopic rooms, $99 \%$ of the studies are performed digitally.

Digital fluoroscopic systems were thought to be reliable and did not increase room down time (Table 3). Seven of 12 respondents believed that digital fluoroscopy increased service and maintenance costs.

Of the 14 hospitals with digital fluoroscopy, five retained $100 / 105 \mathrm{~mm}$ film capability in the room. Three of these five institutions would not purchase a $100 \mathrm{~mm} / 105 \mathrm{~mm}$ camera for future digital fluoroscopic rooms (Table 3 ).

Eleven potential benefits of digital fluoroscopy were scored by the 14 institutions (Table 4). The most important benefits were decreased patient radiation dose, immediate visualization of the acquired image on the TV monitor, and the ability to alter image contrast and density. The three least important benefits were the ability to network images, the potential to decrease costs of fluoroscopic studies, and additional diagnostic information.

From the Department of Radiology, Riley Hospital for Children, Indianapolis, IN.

Address reprint requests to Mervyn D. Cohen, MD, Department of Radiology, Riley Hospital for Children, 702 Barnhill Dr, Indianapolis, IN 46202.

Copyright $\odot 1992$ by W.B. Saunders Company

0897-1889/92/0502-0009\$03.00/0 
Table 1. Hospitals With Digital Fluoroscopy

\begin{tabular}{ccc}
\hline & $\begin{array}{c}\text { No. of Hospital } \\
\text { Beds \{mean } \pm \text { SD) }\end{array}$ \\
\hline Yes & 14 & $248 \pm 88$ \\
No & 25 & $183 \pm 69$ \\
\hline
\end{tabular}

The method of use of the digital fluoroscopic system is summarized in Table 5. There is marked uniformity. All of the institutions use hardcopy for long-term storage. Almost all use a laser printer to produce this hardcopy. Most institutions print only selected images although many of them have the ability to batch film all of the acquired images. Only 2 of 14 institutions keep the digital data indefinitely. Only one institution networks images, and this networking is confined within the radiology department.

\section{Computed Radiography}

Only 4 of the 39 institutions reported having computed radiography equipment (Table 6). Three of these use a photostimulable phosphor plate, and one uses a beam scanning technique (Table 7). All four institutions use hardcopy for long-term storage, only one keeps digital data indefinitely, and only one is networking images to intensive care areas in the hospital (Table 7).

Of those hospitals without computed radiography there is a moderate belief that this tech-

Table 2. Twenty-five Hospitals Without Digital Fluoroscopy

\begin{tabular}{ll}
\hline \multicolumn{1}{c}{ Reason } & Mean \pm SD \\
\hline $\begin{array}{l}\text { Computed radiography believed to be } \\
\quad \text { worthwhile }\end{array}$ & $4.4 \pm 0.8$ \\
Plan installation in next 12 mo* & $3.2 \pm 1.7$ \\
Factors limiting purchase & \\
$\quad$ Budget & $2.9 \pm 1.6$ \\
Increased service costs & $2.2 \pm 1.0$ \\
Complex new technology difficult for & \\
$\quad$ technologists & $1.6 \pm 0.8$ \\
\hline
\end{tabular}

NOTE. Maximal score is 5 on a scale of 1 to 5 .

*Nine answers of absolute yes.

Table 3. Fourteen Hospitals With Digital Fluoroscopy

\begin{tabular}{|c|c|c|c|}
\hline Reason & Yes & No & $\begin{array}{c}\text { No } \\
\text { Answer }\end{array}$ \\
\hline System is reliable & 10 & 2 & 2 \\
\hline Significant increase in downtime & 2 & 10 & 2 \\
\hline Increases service/maintenance costs sign & & & \\
\hline cantly & 7 & 5 & 2 \\
\hline $100 / 105 \mathrm{~mm}$ camera in digital room & 5 & 9 & - \\
\hline If yes, would you eliminate $100 / 105 \mathrm{~mm}$ & 3 & 2 & 一 \\
\hline
\end{tabular}

Table 4. Fourteen Hospitals With Digital Fluoroscopy-Perceived Benefits

\begin{tabular}{ll}
\hline \multicolumn{1}{c}{ Benefit } & Mean $\pm \mathrm{SD}$ \\
\hline Decreased radiation dose & $4.8 \pm 0.4$ \\
Immediate visualization of acquired image & \\
$\quad$ on TV monitor & $4.2 \pm 0.7$ \\
Ability to alter contrast and density & $4.0 \pm 1.2$ \\
Improved image quality & $3.9 \pm 1.2$ \\
More stable image quality & $3.8 \pm 1.2$ \\
Ability to edge enhance images & $3.4 \pm 1.4$ \\
Improved patient throughput & $3.1 \pm 1.5$ \\
Elimination of dark room & $3.0 \pm 1.7$ \\
Improved diagnostic information & $2.8 \pm 1.3$ \\
Decreased costs of fluoroscopic studies & $2.6 \pm 1.5$ \\
Ability to network images to other areas of & \\
$\quad$ hospital & $2.2 \pm 1.4$ \\
\hline
\end{tabular}

NOTE. Maximal score is 5 on a scale of 1 to 5 .

Table 5. Fourteen Hospitals With Digital Fluoroscopy

\begin{tabular}{lccc}
\hline \multicolumn{1}{c}{ Reason } & Yes & No & $\begin{array}{c}\text { No } \\
\text { Answer }\end{array}$ \\
\hline Purchased as an integrated system & 11 & 3 & 0 \\
Use hardcopy for long-term storage & 14 & 0 & 0 \\
Use laser camera for hardcopy & 13 & 1 & 0 \\
Print only selected images & 10 & 3 & 1 \\
Have batch filming capability & 11 & 1 & 2 \\
Keep digital data indefinitely & 2 & 12 & 0 \\
Networking images & $1^{*}$ & 13 & 0 \\
\hline
\end{tabular}

*Only within radiology department.

Table 6. Hospitals With Computed Radiography

\begin{tabular}{ccc}
\hline Yes & $4^{*}$ \\
No & 30 \\
No answer & 5 \\
\hline *Mean, 158 beds (mean of all study hospitals is 206 beds). \\
Table 7. Four Hospittals With Computed Radiography \\
\hline \multicolumn{4}{c}{ Method } & Yes & No \\
\hline Phosphor plate system & 3 & 1 \\
Use hard copy for long-term storage & 4 & 0 \\
Keep digital data indefinitely & 1 & 3 \\
Networking images to wards & 1 & 3 \\
\hline
\end{tabular}

Table 8. Thirty-five Hospitals Without Computed Radiography

\begin{tabular}{ll}
\hline \multicolumn{1}{c}{ Reason } & Mean + SD \\
\hline $\begin{array}{l}\text { Computed radiography believed to be } \\
\text { worthwhile }\end{array}$ & $3.9 \pm 1.1$ \\
Plan installation in next 12 months & $2.3 \pm 1.6$ \\
Factors limiting purchase & \\
$\quad$ Budget & $3.7 \pm 1.5$ \\
Increased service costs & $3.0 \pm 1.3$ \\
$\quad$ Complex new technology difficult for & \\
$\quad$ technologists & $2.1 \pm 1.1$ \\
\hline
\end{tabular}

NOTE. Maximal score is 5 on a scale of 1 to 5 . 


\begin{tabular}{ll}
\multicolumn{2}{c}{$\begin{array}{c}\text { Table 9. } 4 \text { Hospitals With Computed } \\
\text { Radiography-Perceived Benefits }\end{array}$} \\
\hline More stable image quality & 4.7 \\
Ability to alter contrast and density & 4.5 \\
Image transfer to remote areas & 4.5 \\
Improved image quality & 4.3 \\
Ability to edge enhance images & 4.0 \\
Increased diagnostic information & 4.0 \\
Decreased radiation dose & 4.0 \\
\hline
\end{tabular}

NOTE. Maximal score is 5 on a scale of 1 to 5 .

nology is worthwhile, but little intention of installing such a system in the next 12 months because of budgetary restraints (Table 8 ).

All seven potential benefits of computed radiography were scored very highly by the four institutions using this technology (Table 9).

\section{DISCUSSION}

It is now possible to plan a totally digital radiology department. ${ }^{1}$ Pediatric radiologists are beginning to use the two newest digital modalities, digital fluoroscopy and computed radiography. Digital fluoroscopy is more widely used both in terms of the installed base and planned installations in the next 12 months. The explanation for this would appear to be the greater cost of computed radiography as compared with that of digital fluoroscopy. The cost of incorporating digital capability into a new fluoroscopic room, particularly if the $100 \mathrm{~mm}$ / $105 \mathrm{~mm}$ camera is eliminated, is probably less than $10 \%$ of that of installing a computed radiography system for plain film radiographs.
Digital fluoroscopy is perceived as offering distinct benefits, the most important of which are decreased radiation dose, the immediate visualization of the acquired image on the television monitor, and the ability to alter image contrast and density. Improved diagnostic information is not a major reason for using digital fluoroscopy.

Computed radiography is well liked by those hospitals that have it. Its potential benefits (Table 9) were all ranked highly. Unlike digital fluoroscopy, computed radiography is believed to offer the potential of increased diagnostic information.

There is similarity in the method of use of these digital imaging systems. Almost all of the institutions are using hardcopy for long-term storage with little long-term retention of digital data. Only one institution has any form of a picture archiving communication systems (PACS) network outside of the radiology department, with networking of images by this institution to intensive care areas. ${ }^{4}$ Thus, PACS networking does not appear to be a major force driving the purchase and installation of digital systems.

Installation and use of digital fluoroscopy and computed radiography in pediatric hospitals will almost certainly increase but with budget limitations hindering expansion. Institutions with such systems perceive them very favorably and many institutions without such systems desire to purchase them.

\section{REFERENCES}

1. Huang HK, Kangarloo H, Cho PS, et al: Planning a totally digital radiology department. AJR 154:635-639, 1990

2. Cohen MD, Long B, Cory DA, et al: Digital imaging of the newborn chest. Clin Radiol 40:365, 1989

3. Hynes DM, Rowlands JA, Edmonds EW: Clinical comparison of analog and digital $100 \mathrm{~mm}$ photofluorography. J Can Assoc Radiol 40:262, 1989

4. Witt RM, Cohen MD, Appledorn CR: Initial experience with a radiology imaging network to newborn and intensive care units. J Digital Imag 4:39-42, 1991 